\title{
Titanium-enriched medium drives low profile of ECM remodeling as a pre- requisite to pre-osteoblast viability and proliferative phenotype
}

\author{
Celio J. da Costa Fernandes ${ }^{\mathrm{a}}$, Fábio J.B. Bezerra ${ }^{\mathrm{a}}$, Bruno de Campos Souza ${ }^{\mathrm{a}}$, \\ Mônica Aparecida Campos ${ }^{\mathrm{a}}$, Willian Fernando Zambuzzi ${ }^{\mathrm{a}, \mathrm{b}, *}$ \\ a Dept. of Chemistry and Biochemistry, Bioscience Institute, São Paulo State University, UNESP, Campus Botucatu, Botucatu, São Paulo, Brazil \\ ${ }^{\mathrm{b}}$ Electron Microscopy Center, IBB, UNESP, Botucatu, SP, Brazil
}

\section{A R T I C L E I N F O}

\section{Keywords:}

Pre-osteoblast

Cell signalling

Cell adhesion

Titanium

Extracellular matrix

\begin{abstract}
A B S T R A C T
Titanium is widely used for biomedical applications, but little information is being delivered regarding the cellular/molecular mechanisms explaining their efficacy, mainly considering the effects of the Ti-released trace elements on pre-osteoblasts. We addressed this issue by investigating decisive intracellular signal transduction able to modulate cytoskeleton rearrangement, proliferative phenotype and extracellular matrix (ECM) remodeling. We considered titanium grades IV and V, submitted or not to dual acid-etching (w/DAE or wo/DAE, respectively). Our results showed there is no cytotoxicity, preserving AKT involvement. Additionally, Ti-enriched medium promoted a diminution of the downstream signaling upon integrin activation (phosphorylating Rac1 and cofilin), guaranteeing a dynamic cytoskeleton rearrangement. Moreover, the low profile of ECM remodeling obtained in response to trace molecules released by Ti-based devices seems contributing to the osteoblast performance in mediating extracellular support to cell anchorage. This hypothesis was validated by the up-expression of $\beta 1$-integrin, $s r c$ and Focal adhesion kinase ( $f a k$ ) genes, mainly in response to titanium grade V.

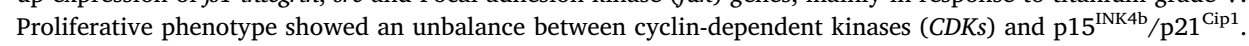
In conjunction, we showed for the first time that trace elements from Ti-based biomedical devices provoke important modulation of the osteoblast biology, driving cell anchoring, viability, and proliferative phenotype. Certainly, these biological outcomes compromise implant osseointegration.
\end{abstract}

\section{Introduction}

In decades, metallic materials have been used in dentistry and medicine as implants devices [1,2]. Titanium alloys are widely used in biomedical practice reaching high success rates, mainly due to its characteristics of high corrosion resistance, low toxicity, very low allergenic potential and biocompatibility. Although titanium being considered an inert implantable material, we have reported its capacity in dynamically modulate surrounding tissue by modifying the metabolism of pre-osteoblast and interfering on crucial intracellular signal transduction pathways [3]. However, little progress about the trace elements from titanium-based devices has been achieved. In addition, bone repair surrounding the implants requires a well-defined biological sequence considering the interaction of pre-osteoblasts with the surface of implanted materials, guaranteeing the expected osseointegration [4]. To note, it is clear that osseointegration process requires cell adhesion, proliferation and differentiation and these cellular mechanisms are strictly guided by intracellular signal transduction mechanisms [5], which respond to diverse stimuli, such as the chemical properties of material surfaces as well as to immediately adsorbed serum's protein onto the surface's implant [6].

Thus, dental implants-related topography is fundamental for the initial stages of the osteoblast adaptation, affecting cell adhesion and further differentiation as well as in long-term bone remodeling $[7,8]$. Surface modification of implants is a traditional strategy to improve titanium surface properties, mainly considering their consequence on cell behavior and late tissue regeneration surrounding them. This dynamic effect on the surrounding tissue must be even more concerned if bring to light that bone remodeling continues lifelong [9]. It is growing the interest in proposing novel technologies on implant surfaces in order to optimize osteoblast performance. A well-accepted micro-scaled surface is the result of a subsequent acid-etching (DAE) by using $\mathrm{HCl}$ / $\mathrm{H}_{2} \mathrm{SO}_{4}$ [10], resulting in an bioactive surface presenting Sa parameter around $1.3 \mu \mathrm{m}$ and significantly interfering cell adhesion and

\footnotetext{
* Corresponding author at: Bioassays and Dynamic Cell Lab Dept. of Chemistry and Biochemistry, Bioscience Institute; São Paulo State University - UNESP, campus Botucatu Street: Professora Doutora Irina Delanova Gemtchujnicov, Botucatu, São Paulo 18618-693 Brazil. Phone: +55 14 $3880-0599$.

E-mail address: w.zambuzzi@unesp.br (W.F. Zambuzzi).
} 
consequently guiding osseointegration process [11]. In distance, bonehealing process requires osteoblasts migration leading to the bone neoformation at an appositional manner towards the implant [7]. In this scenario, we reported elsewhere the capacity of trace elements released from dental implants in governing osteoblast metabolism [12]. Although some progress has been made on this scenario to understand osteoblast behavior in response to titanium biomaterials, titanium alloys is presented in different compositions and there is interest to comprehend eventual biological responses to them.

Based on the above-mentioned, the general objective of this study was to revisit the classical double-acid etching (DAE) obtained by using both titanium grades IV and V, comparing to machined titanium surface (control), by exploring a specific molecular machinery in osteoblast behavior and report about their biocompability. Summarizing, our results showed there is a rigorous hierarchical intracellular mechanism resulting in cytoskeleton rearrangement-based cell adhesion involving Rac-1/cofilin pathway. Additionally, survival Akt protein remained active, cell cycle progression was positively modulated, and low profile of the extracellular matrix (ECM) remodeling was observed. Partially, the results might explain the dynamic effect of trace elements-released from dental implants in the surrounding cells, proposing a set of biological event to be considered during the development of smart biomaterial's surfaces.

\section{Material and methods}

\subsection{Materials}

Implants - titanium grades IV and V, with dual acid-etching (W/ DAE) and without dual acid-etching (Wo/DAE), were donated by SIN Implant System company (SIN), São Paulo-Brazil. Antibodies - the following antibodies were purchased from Cell Signaling (Danvers, MA, USA): Rac1/cdc42 Antibody (\#4651, $21 \mathrm{kDa),} \mathrm{Phospho-Rac1/cdc42}$ (Ser71) Antibody (\#2461, $28 \mathrm{kDa}$ ), GAPDH Rabbit (\#5174, $37 \mathrm{kDa)}$ and from Abcam (Cambridge, MA, USA): anti-Cofilin antibody (ab42824), anti-Cofilin (phospho S3) (\#3311). The primers used in this study were purchased from Exxtend Solutions in OLIGOS (Campinas, São Paulo, Brazil) and the experimental conditions of the qPCR are described in Table 1.

\subsection{Cell culture}

MC3T3-E1 cells, pre-osteoblasts, subclone 4, were used in this study. During all experiments, the cells were maintained in aMEM containing antibiotics (100U/ml penicillin, $100 \mathrm{mg} / \mathrm{ml}$ streptomycin) and Ribonucleosides and Deoxyribonucleosides. The medium was also supplemented with $10 \%$ Fetal Bovine Serum (Nutricell, Campinas, SP, Brazil). Routinely, pre-osteoblasts were maintained at $37^{\circ} \mathrm{C}$ and at $5 \%$ $\mathrm{CO}_{2}$ and 95\% humidity, and the medium was freshly changed every each 3 days.

\subsection{Experimental design}

Different titanium discs were individually incubated for $24 \mathrm{~h}$ in FBSfree cell culture medium $(0.01 \mathrm{mg} / \mathrm{mL}$, which the diameter is $0.6 \mathrm{~cm})$, as established by ISO 10993-5:2016. After conditioning, the medium was named as Ti-enriched medium, since containing trace molecules from the titanium discs. This Ti-enriched medium was used to treat semiconfluent pre-osteoblasts cultures in order to investigate specific molecular aspects involved in this acute response (Fig. 1).

\subsection{Cell viability assay}

Semiconfluent cultures were subjected to Ti-enriched medium up to $24 \mathrm{~h}$. Thereafter, the medium was replaced by cell medium-containing a vital dye MTT $(1 \mathrm{mg} / \mathrm{mL})$ and they were maintained by additional $3 \mathrm{~h}$ in
Table 1

Expression primers sequences and PCR cycle conditions.

\begin{tabular}{|c|c|c|c|}
\hline Gene & Primer & 5'-3' Sequence & $\begin{array}{l}\text { Reactions } \\
\text { Condition }\end{array}$ \\
\hline \multirow[t]{2}{*}{ mmp2 } & Forward & AACTTTGAGAAGGATGGCAAGT & $95^{\circ} \mathrm{C}-3 \mathrm{~s} ; 55^{\circ} \mathrm{C}-$ \\
\hline & Reverse & TGCCACCCATGGTAAACAA & $8 \mathrm{~s} ; 72{ }^{\circ} \mathrm{C}-20 \mathrm{~s}$ \\
\hline \multirow[t]{2}{*}{$m m p 9$} & Forward & TGTGCCCTGGAACTCACACGAC & $95^{\circ} \mathrm{C}-3 \mathrm{~s} ; 55^{\circ} \mathrm{C}-$ \\
\hline & Reverse & ACGTCGTCCACCTGGTTCACCT & $8 \mathrm{~s} ; 72^{\circ} \mathrm{C}-20 \mathrm{~s}$ \\
\hline \multirow[t]{2}{*}{ timp1 } & Forward & ATCCTCTTGTTGCTATCACTG & $95^{\circ} \mathrm{C}-5 \mathrm{~s} ; 56^{\circ} \mathrm{C}-$ \\
\hline & Reverse & GGTCTCGTTGATTTCTGGG & $10 \mathrm{~s} ; 72^{\circ} \mathrm{C}-15 \mathrm{~s}$ \\
\hline \multirow[t]{2}{*}{ timp2 } & Forward & GCAACAGGCGTTTTGCAATG & $95^{\circ} \mathrm{C}-3 \mathrm{~s} ; 55^{\circ} \mathrm{C}-$ \\
\hline & Reverse & CGGAATCCACCTCCTTCTCG & $8 \mathrm{~s} ; 72^{\circ} \mathrm{C}-20 \mathrm{~s}$ \\
\hline \multirow[t]{2}{*}{$\beta 1$-integrin } & Forward & CTGATTGGCTGGAGGAATGT & $95^{\circ} \mathrm{C}-3 \mathrm{~s} ; 60^{\circ} \mathrm{C}-$ \\
\hline & Reverse & TGAGCAATTGAAGGATAATCATAG & $8 \mathrm{~s} ; 72^{\circ} \mathrm{C}-20 \mathrm{~s}$ \\
\hline \multirow[t]{2}{*}{$s r c$} & Forward & TCGTGAGGGAGAGTGAGAC & $95^{\circ} \mathrm{C}-3 \mathrm{~s} ; 60^{\circ} \mathrm{C}-$ \\
\hline & Reverse & GCGGGAGGTGATGTAGAAAC & $8 \mathrm{~s} ; 72^{\circ} \mathrm{C}-20 \mathrm{~s}$ \\
\hline \multirow[t]{2}{*}{ fak } & Forward & TCCACCAAAGAAACCACCTC & $95^{\circ} \mathrm{C}-3 \mathrm{~s} ; 60^{\circ} \mathrm{C}-$ \\
\hline & Reverse & ACGGCTTGACACCCTCATT & $8 \mathrm{~s} ; 72{ }^{\circ} \mathrm{C}-20 \mathrm{~s}$ \\
\hline \multirow[t]{2}{*}{$c d k 2$} & Forward & TACCCAGTACTGCCATCCGA & $\begin{array}{l}95^{\circ} \mathrm{C}-3 \mathrm{~s} ; 60^{\circ} \mathrm{C}- \\
8 \mathrm{~s} ; 72^{\circ} \mathrm{C}-20 \mathrm{~s}\end{array}$ \\
\hline & Reverse & CGGGTCACCATTTCAGCAAA & \\
\hline \multirow[t]{2}{*}{$c d k 4$} & Forward & TCGATATGAACCCGTGGCTG & $\begin{array}{l}95^{\circ} \mathrm{C}-3 \mathrm{~s} ; 60^{\circ} \mathrm{C}- \\
8 \mathrm{~s} ; 72^{\circ} \mathrm{C}-20 \mathrm{~s}\end{array}$ \\
\hline & Reverse & TTCTCACTCTGCGTCGCTTT & \\
\hline \multirow[t]{2}{*}{$c d k 6$} & Forward & CGCCGATCAGCAGTATGAGT & $\begin{array}{l}95^{\circ} \mathrm{C}-3 \mathrm{~s} ; 60^{\circ} \mathrm{C}- \\
8 \mathrm{~s} ; 72{ }^{\circ} \mathrm{C}-20 \mathrm{~s}\end{array}$ \\
\hline & Reverse & GCCGGGCTCTGGAACTTTAT & \\
\hline \multirow[t]{2}{*}{ p15 } & Forward & GGGCAAGTGGAGACGGTG & $95^{\circ} \mathrm{C}-3 \mathrm{~s} ; 60^{\circ} \mathrm{C}-$ \\
\hline & Reverse & ACCCCCGCTACCTGGATT & $8 \mathrm{~s} ; 72^{\circ} \mathrm{C}-20 \mathrm{~s}$ \\
\hline \multirow[t]{2}{*}{ p21 } & Forward & CGCCGATCAGCAGTATGAGT & $95^{\circ} \mathrm{C}-3 \mathrm{~s} ; 60^{\circ} \mathrm{C}-$ \\
\hline & Reverse & GCCGGGCTCTGGAACTTTAT & $8 \mathrm{~s} ; 72^{\circ} \mathrm{C}-20 \mathrm{~s}$ \\
\hline \multirow[t]{2}{*}{ cofilin } & Forward & CAGACAAGGACTGCCGCTAT & $95^{\circ} \mathrm{C}-3 \mathrm{~s} ; 60^{\circ} \mathrm{C}-$ \\
\hline & Reverse & TTGCTCTTGAGGGGTGCATT & $8 \mathrm{~s} ; 72{ }^{\circ} \mathrm{C}-20 \mathrm{~s}$ \\
\hline \multirow[t]{2}{*}{$\beta$-actin } & Forward & TCTTGGGTATGGAATCCTGTG & $95^{\circ} \mathrm{C}-3 \mathrm{~s} ; 60^{\circ} \mathrm{C}-$ \\
\hline & Reverse & AGGTCTTTACGGATGTCAACG & $8 \mathrm{~s} ; 72^{\circ} \mathrm{C}-20 \mathrm{~s}$ \\
\hline \multirow[t]{2}{*}{$18 s$} & Forward & CGCTATCTGACTCGCTG & $95^{\circ} \mathrm{C}-3 \mathrm{~s} ; 60^{\circ} \mathrm{C}-$ \\
\hline & Reverse & GGAAGGTTCTAGTCAGG & $8 \mathrm{~s} ; 72^{\circ} \mathrm{C}-20 \mathrm{~s}$ \\
\hline \multirow[t]{2}{*}{ gapdh } & Forward & AGGCCGGTGCTGAGTATGTC & $95^{\circ} \mathrm{C}-3 \mathrm{~s} ; 60^{\circ} \mathrm{C}-$ \\
\hline & Reverse & TGCCTGCTTC ACCACCTTCT & $8 \mathrm{~s} ; 72^{\circ} \mathrm{C}-20 \mathrm{~s}$ \\
\hline
\end{tabular}

cell culture incubator. Thereafter, the MTT medium was aspired out and the blue precipitate dye diluted in $100 \mu \mathrm{L} /$ well of DMSO, when the cell viability was estimated by measuring the absorbance in a microplate reader (SYNERGY-HTX multi-mode reader, Biotek, USA) at $570 \mathrm{~nm}$ wavelength.

\subsection{Sample preparation and immunoblotting}

Semiconfluent cultures of pre-osteoblasts were subjected to Ti-enriched medium up to $24 \mathrm{~h}$, when the pre-osteoblasts were lysed [50 $\mathrm{mM}$ Tris-HCl, pH 7.4, 1\% Tween 20, 0.25\% Sodium deoxycholate, $150 \mathrm{mM}$ $\mathrm{NaCl}, 1 \mathrm{mM}$ EGTA, $1 \mathrm{mM}$ O-Vanadate, $1 \mathrm{mM} \mathrm{NaF}$, and protease inhibitors $(1 \mu \mathrm{g} / \mathrm{ml}$ aprotinin, $10 \mu \mathrm{g} / \mathrm{ml}$ leupeptin and $1 \mathrm{mM}$ aminoethyl fluorosilicon 4-fluoride hydrochloride)]. Thereafter, the samples were sonicated ( 1 pulse per second; SONICS Vibra-Cell) and the protein extracts centrifuged. To note, the protein concentration was determined by the Lowry method [13]. Thereafter, to cell extracts were added an equal volume of Laemmli buffer [2X sodium dodecyl sulfate (SDS), 100 mM Tris- $\mathrm{HCl}$ (pH 6.8), 200 mM dithiothreitol (DTT), 4\% SDS, $0.1 \%$ bromophenol blue and $20 \%$ glycerol]. Lastly, the samples were boiled at $95^{\circ}$ up to $5 \mathrm{~min}$. Protein extracts were resolved by SDS-PAGE $(10 \%$ or $12 \%$ ) and transferred to PVDF membranes (Millipore). Membranes were blocked with either $1 \%$ fat-free dried milk or bovine serum albumin (2.5\%) in Tris-buffered saline (TBS)-Tween-20 (0.05\%) and incubated overnight at $48 \mathrm{C}$ with appropriate primary antibody at 1:1.000 dilutions. After washing in TBS-Tween-20 (0.05\%), membranes were incubated with horseradish peroxidase- conjugated anti-rabbit, antigoat, or anti-mouse IgGs antibodies, at 1:2.000 dilutions (in all immunoblotting assays), in blocking buffer for $1 \mathrm{~h}$. Detection was performed by using enhanced chemiluminescence (ECL). For all Western 


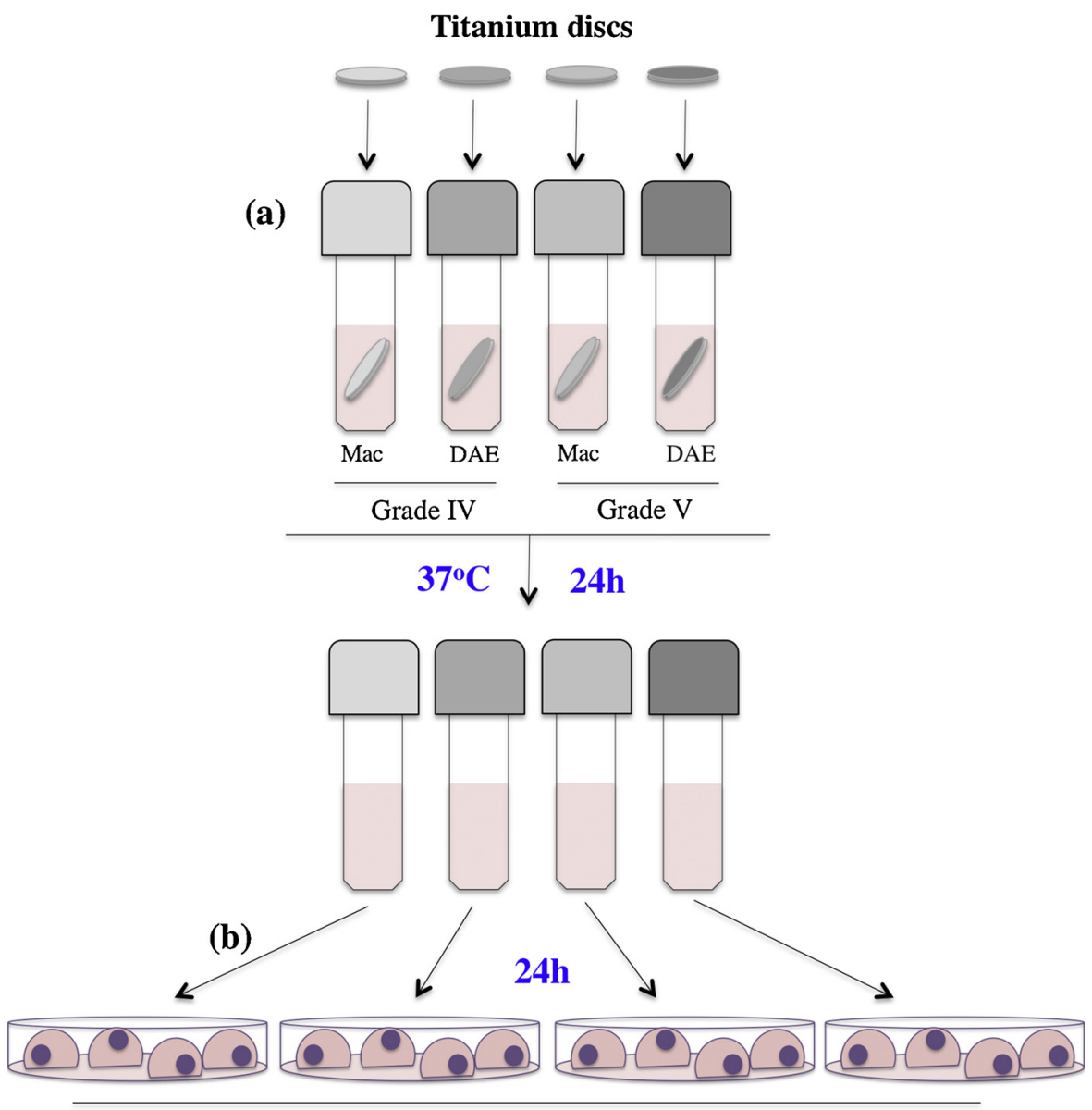

(c) Challenged cells

(d) Samples preparation for cellular and molecular analyses

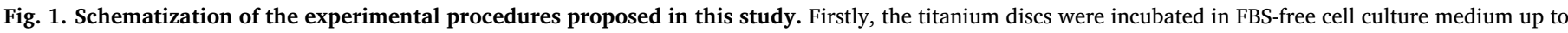

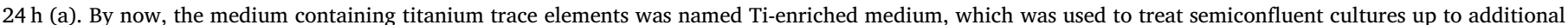
$24 \mathrm{~h}$ (b), when challenged pre-osteoblasts (c) were properly processed to obtaining samples to different biochemical methodologies (d).

blots $-\beta$-actin was used as an (additional) internal control.

\section{6. $R T-q P C R$}

By considering the same experimental protocol, the cells were harvested in TriZOL, exactly as recommended by the manufacturer. Total mRNA samples were quantitated using microplate reader (SYNERGY-HTX multi-mode reader, Biotek, Tigan St, Winooski, USA). The cDNA synthesis was performed using the High-Capacity cDNA Reverse Transcription Kits kit (Applied Biosystems, Foster City, CA, USA). For each gene evaluated here, we have used 3 reference genes to normalize the transcripts profile, as follows: gapdh, $\beta$-actin and $18 \mathrm{~s}$. Thereafter, the pool of cDNA was used to evaluate specific gene's expression (Table 1).

\subsection{Matrix metalloproteinase activities}

Thereafter, we decided to investigate whether the MMP's activities were modified in response to Ti-enriched medium by exploring zymography approach. The pre-osteoblast cultures were treated as detailed previously up to $24 \mathrm{~h}$ when the conditioned medium (cell supernatants) was collected to determine MMP2 activity. The gelatinolytic activities of the samples were evaluated by resolving the samples in SDS-PAGE ( $10 \%$ polyacrylamide) containing $0.1 \%$ gelatin. Previously, the samples were mixed with loading buffer ( $2 \%$ SDS and $0.1 \%$ bromophenol blue) and electrophoresed under non-reducing condition. After electrophoresis, gels were washed in $2 \%$ Triton X-100 and immersed in buffer containing $50 \mathrm{mM}$ Tris- $\mathrm{HCl}$ ( $\mathrm{pH}$ 7.6), $200 \mathrm{mM} \mathrm{NaCl}, 10 \mathrm{mM} \mathrm{CaCl} 2$ for $18 \mathrm{~h}$ at $37^{\circ} \mathrm{C}$. The gels were stained with $0.5 \%$ Coomassie Blue G-250 in acetic acid/methanol/water (1:4:5 vol/vol/vol) and destained in acetic $\mathrm{acid} / \mathrm{methanol} /$ water (1:2:7 $\mathrm{vol} / \mathrm{vol} / \mathrm{vol})$.

\subsection{Confocal microscopy}

For confocal microscopy analysis, the cells were grown on glass coverslips. Adherent cells subjected to Ti-enriched medium were washed with PBS, fixed in phosphate-buffered paraformaldehyde ( $4 \% \mathrm{v} / \mathrm{v})$ for $1 \mathrm{~h}$, permeabilized in phosphate buffer containing $0.2 \%$ Triton-X 100 and $1 \%$ BSA at $37^{\circ} \mathrm{C}$ for $1 \mathrm{~h}$. For actin cytoskeletal rearrangement analyzes, the cells were incubated for $40 \mathrm{~min}$ in Alexa Fluor 488-labeled phalloidin $(10 \mu \mathrm{g} / \mathrm{ml}$, Invitrogen/Molecular Probes, USA). The coverslips containing probed cells were washed and mounted on glass slides 
a)

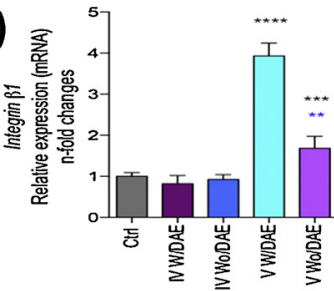

b)

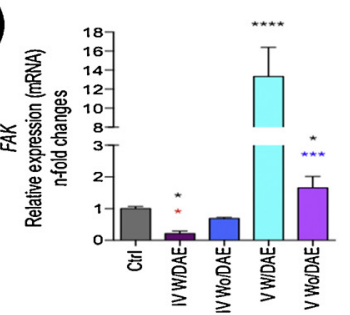

c)

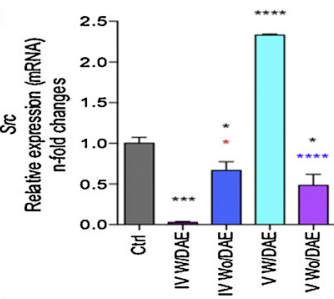

d)

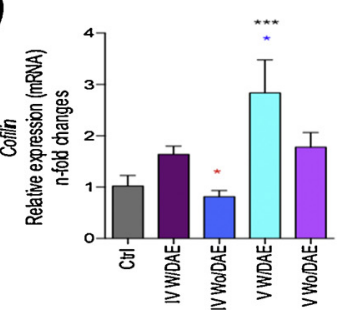

e)

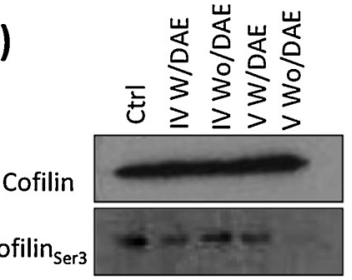

$19 \mathrm{kDa}$ $19 \mathrm{kDa}$

f)

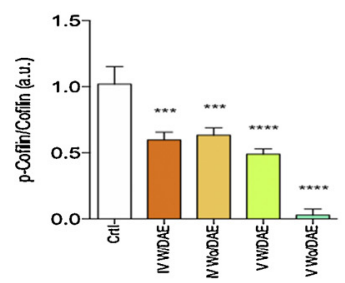

g)

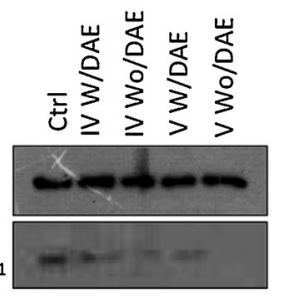

h)

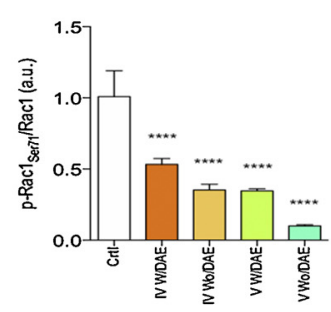

$21 \mathrm{kDa}$ $28 \mathrm{kDa}$ i)

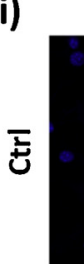

DAPI PHALLOIDIN MERGE
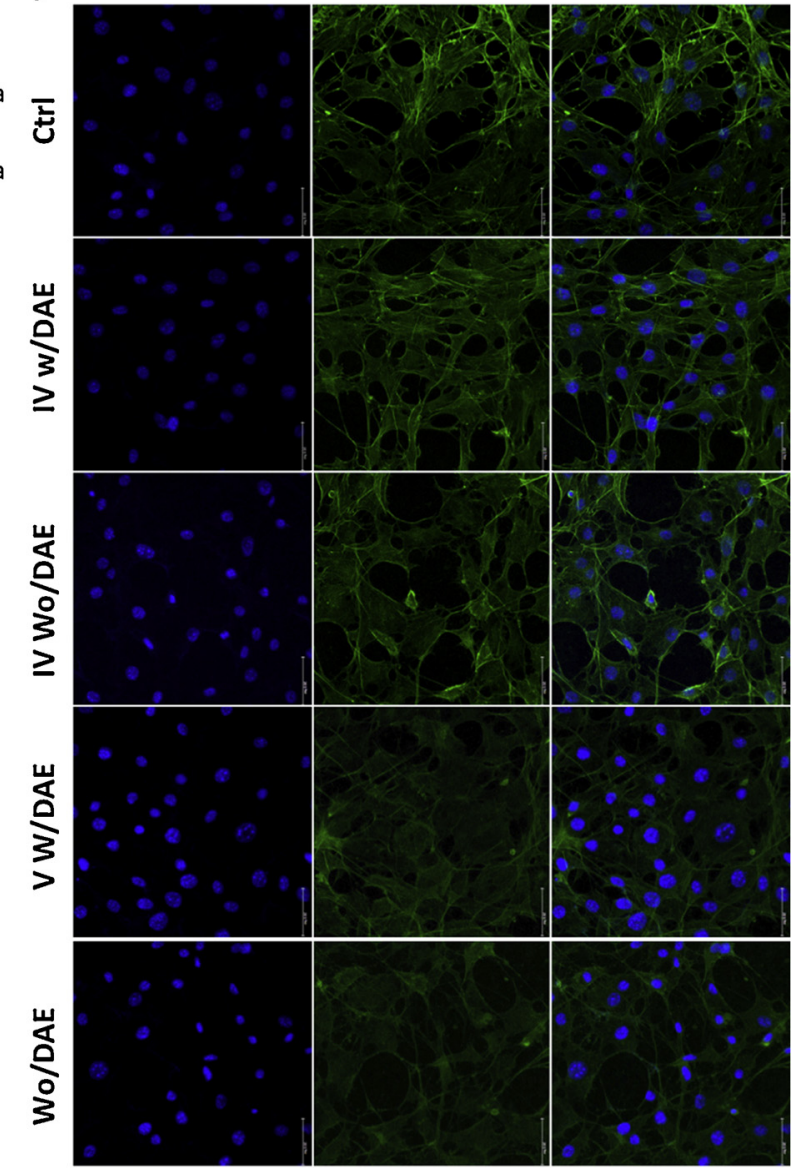

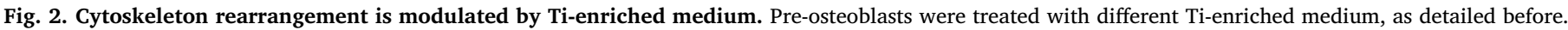

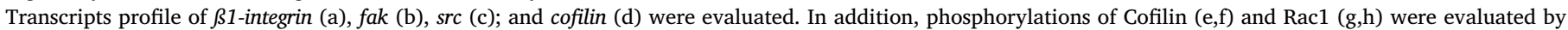

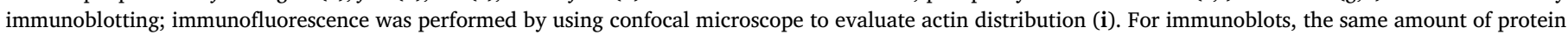

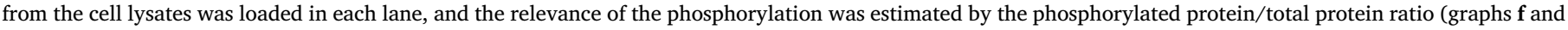

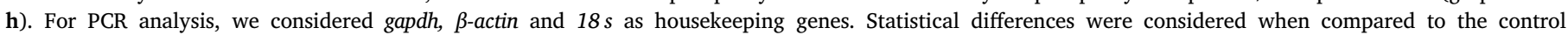

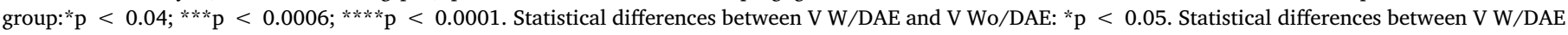
and V Wo/DAE: *p $<0.04 ; * * \mathrm{p}<0.0019 ;{ }^{* * * \mathrm{p}}<0.0006$; ****p $<0.0001$.

using Fluorosield with DAPI (Sigma-Aldrich Corporation St Louis, MO, EUA) and then viewed on an inverted laser scanning confocal microscope (Leica TCS SP5, Allendale, USA).

\subsection{Statistical analysis}

Densitometry analysis of the immunoblots bands were done and the arbitrary values were represented as mean \pm standard deviation (SD). They were verified using student's $t$-test (2-tailed) with $\mathrm{p}<0.05$ considered statistically significant and $\mathrm{p}<0.001$ considered highly significant. In experiment where there were $>2$ groups, we used one way ANOVA (non parametric) with post-test of Bonferroni, in order to compare all pairs of groups. In this case, the significance level was considered when $\alpha=0.05$ (95\% confidence interval). The software used was GraphPad Prism 6.

\section{Results}

Our biological model predicts understanding the molecular differences in osteoblast behavior when they are subjected to different titanium grades (IV and V)-enriched medium, both presenting or not surface modification by DAE.

\subsection{Titanium grades $I V$ and $V$ differentially affect cytoskeleton rearrangement and adhesion}

Firstly, we considered evaluating the effect of TI-enriched medium on pre-osteoblast adhesion machinery, by testing crucial genes related in this process. Thus, we showed there are significant differences on $\beta 1$ integrin transcripts profile comparing both titanium grades. In this case Ti grade $\mathrm{V}$ promoted higher expression of $\beta 1$-integrin, it is being even more significant in response to surface with DAE (Fig. 2a). A very similar profile was obtained considering fak (Fig. 2b) and src (Fig. 2c) genes.

In addition, cofilin gene was up-regulated by Ti grade V (Fig. 2d) and as cofilin activity is regulated by phosphorylation at Ser03, we decided to evaluate the profile of cofilin phosphorylation by using immunoblotting technology and our results showed significant decrease of cofilin phosphorylation in response to Ti-enriched medium (Fig. 2e,f), concomitant to the phosphorylation of Rac1 (Fig. 2g,h), a upstream protein involved upon integrin activation. All of these proteins are related with actin-based cytoskeleton rearrangement and it has been validated by subjecting those cells to phalloidin staining. Our images showed there is a dynamic cytoskeleton rearrangement in response to Ti-enriched medium and significant differences might be observed among the groups (Fig. 2i). 
a)

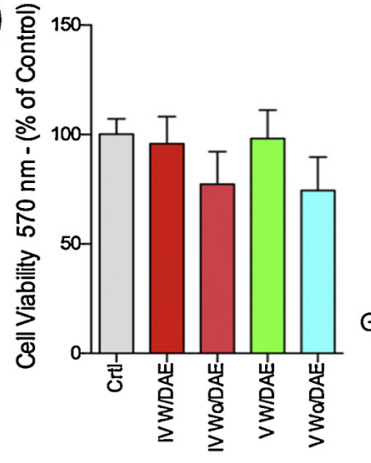

b)

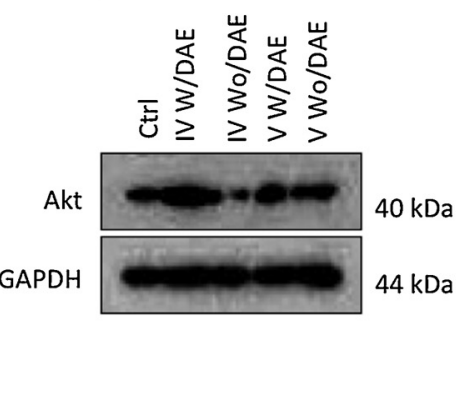

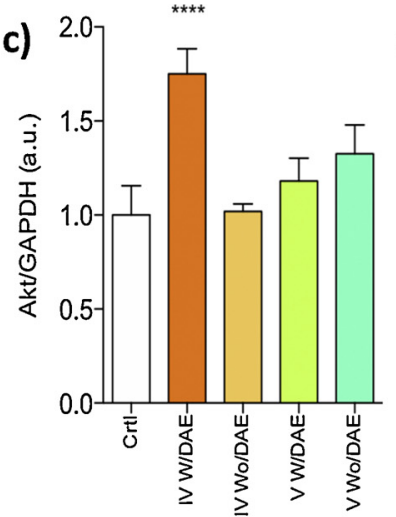

d)

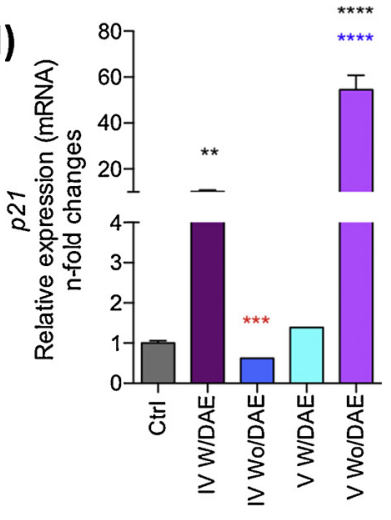

e)

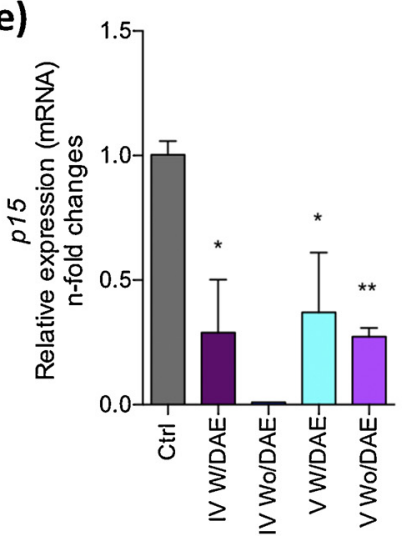

f)

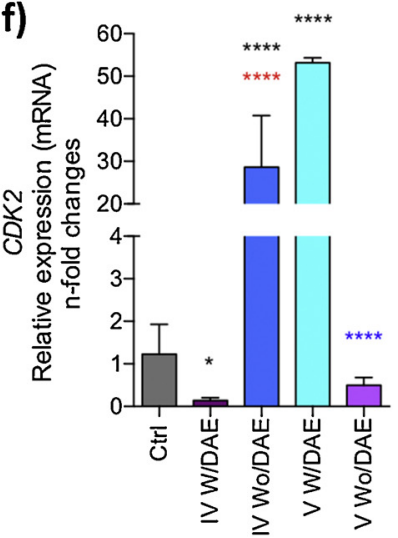

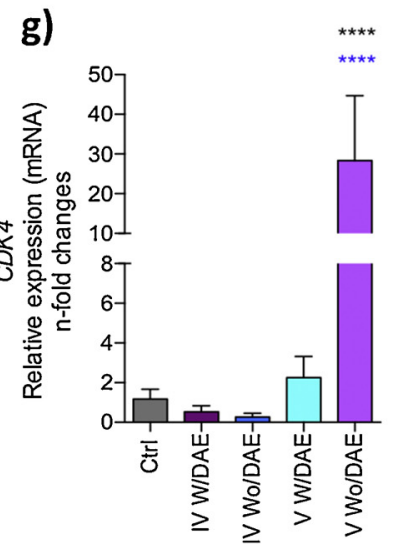

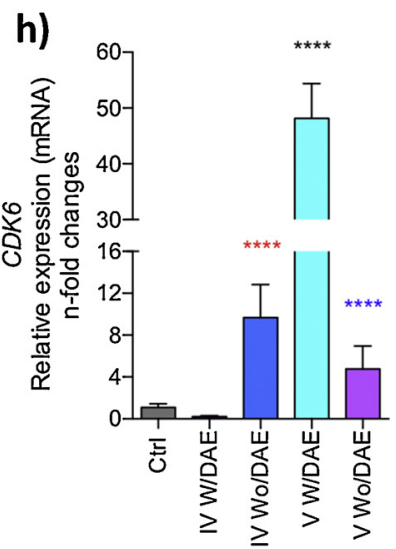

Fig. 3. Ti-enriched medium modulates pre-osteoblast viability and proliferative phenotype. Pre-osteoblasts (MC3T3-E1 cells) were treated with Ti-enriched medium up to $24 \mathrm{~h}$, when the cell viability was measured by MTT approach (a), and the AKT protein profile was estimated (b,c). qPCR methodology was used to estimate the transcriptional profile of $p 21$ (d), $p 15$ (e), $c d k 2$ (f), $c d k 4$ (g), $c d k 6$ (h) genes. For PCR analysis, we considered gapdh, $\beta$-actin and $18 s$ as housekeeping genes. Statistical difference when compared to the control group: *p $<0.04$; **p $<0.0019$; ****p $<0.0001$. Statistical differences between V W/DAE and V Wo/ DAE: ${ }^{* * *} \mathrm{p}<0.0006 ; * * * \mathrm{p}<0.0001$. Statistical differences between V W/DAE and V Wo/DAE: ****p $<0.0001$

\subsection{Variable composition of titanium alloys guarantees pre-osteoblast survival culminating on cell cycle progression}

It is well-established that regenerative mechanism involved with bone growth peri-implant requires pre-osteoblast adhesion, proliferation and differentiation. Here, we evaluated the influence of Ti-enriched medium on pre-osteoblast machinery to guarantee survival and proliferative phenotype. Firstly, cell viability was determined by MTT approach and any cytotoxic effect was found (Fig. 3a), and this profile might be supported by the expression of Akt (Fig. 3b,c). Thereafter, cell cycle-related genes were addressed - p21 gene was differentially affected by the experimental condition proposed here (Fig. 3d), while $p 15$ gene presented down-modulation profile (Fig. 3e). Important, considering $c d k s$ genes, we showed a differential behavior of $c d k s-2,-4$, and -6. Cdk-2 gene was up-expressed in response to Ti grade IV (without DAE) and Ti grade V (with DAE) (Fig. 3f), while $c d k-4$ was up-expressed only in response to Ti grade V without DAE (Fig. 3g). Cdk-6 presented a very similar profile to $c d k-2$ (Fig. $3 \mathrm{~h}$ ).

\subsection{ECM remodeling is dynamically modulated by variable titanium alloys compositions}

As ECM remodeling is a very important step for the adequate osteoblast adaptation on biomaterial's surface, we decided evaluate ECMrelated genes by $\mathrm{qPCR}$ and gelatinolytic activities by zymography technology. Our data showed there is a significant ECM-related genes reprogramming, when $m m p 2$ gene was up-expressed in response to titanium grade IV alloys (Fig. 4a), it being even higher with DAE treatment, while mmp9 (Fig. 4b) and timp1 (Fig. 4c) genes remained unchanged and timp2 transcripts was significantly up-expressed (Fig. 4d). Importantly on this scenario, titanium grade $\mathrm{V}$ promoted an up-modulation of both timp1 (Fig. 4c) and timp2 (Fig. 4d) genes, suggesting a diminution of ECM remodeling, which was validated by the zymogram analysis (Fig. 4e-h). Although MMPs pro-enzyme is higher in response to titanium grade $\mathrm{V}$ than others, this activity is decreased when the active form of MMP enzyme is evaluated (Fig. 4h).

Summarizing, the Fig. 5 brings a draw of the main findings proposed in this study, where it is possible to observe a Ti-released trace elements affect pre-osteoblast metabolism governing ECM remodeling and consequently cytoskeleton rearrangement. Indeed, theses parameters might be correlated with the beginning of proliferative phenotype of pre-osteoblast.

\section{Discussion}

The knowledge about the cellular and molecular behavior in response to titanium devices is urgent once their properties interfere on bone remodeling and health. Over the last few years, we have devoted efforts to purpose in vitro strategies to elucidate intracellular mechanisms triggered by trace elements from different biomaterials, such as hydroxyapatite [14-18], cobalt-chromium [19] and titanium $[6,12,20,21]$. Regarding the titanium alloys, we have shown their capacity in modulating distant cells by releasing molecules, which profoundly affect osteoblast performance, mainly compromising cytoskeleton-related cell adhesion [12]. As titanium alloys are presented in different compositions, we addressed in this study the capacity of titanium-enriched medium obtained from titanium grades IV and V, submitted or not to dual acid-etching (DAE), in modulating osteoblast 

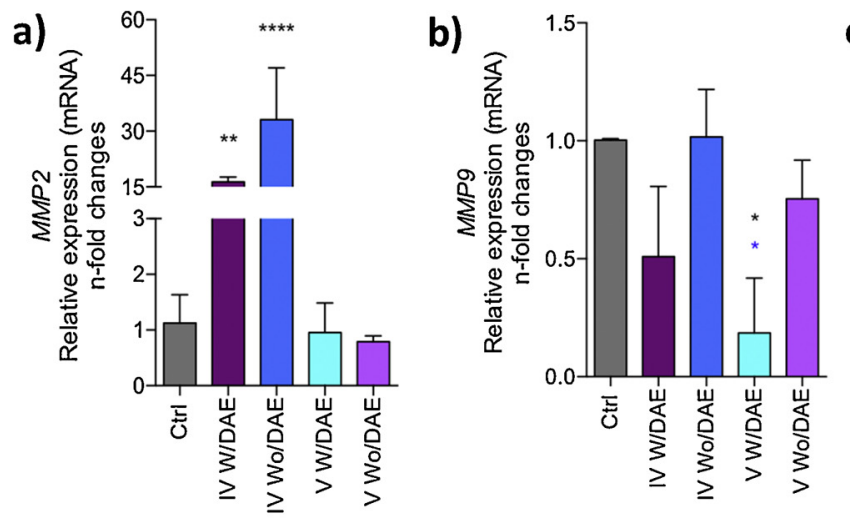

)

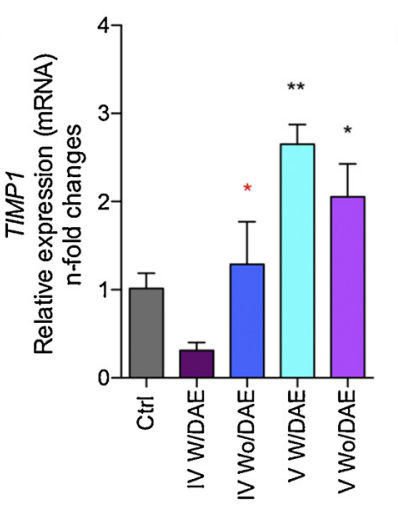

d)
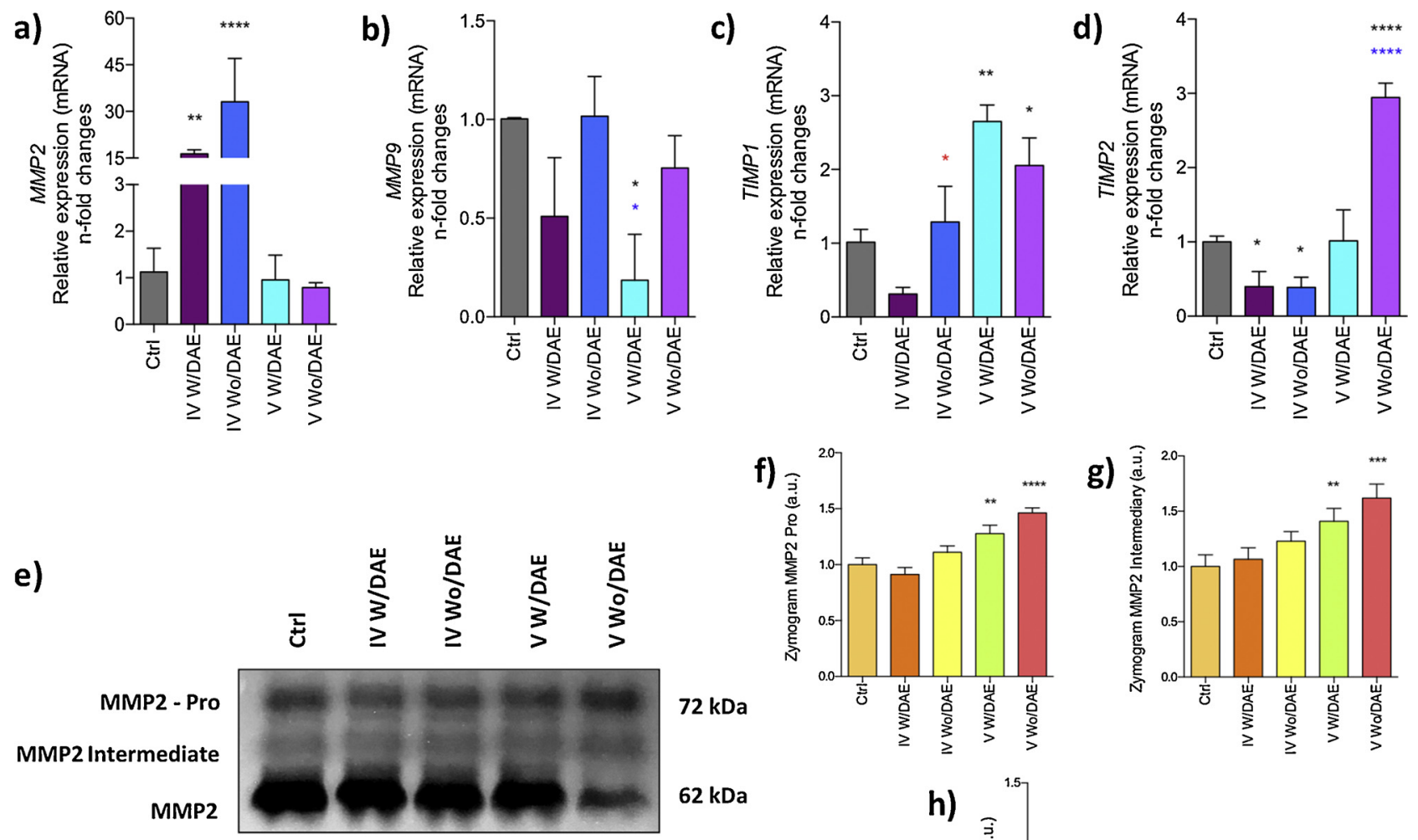

g)

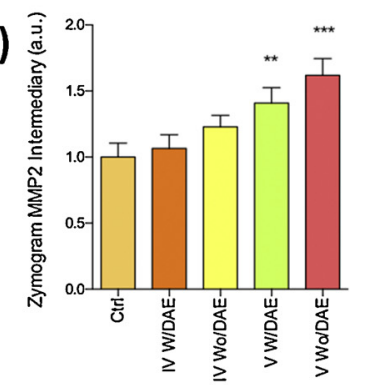

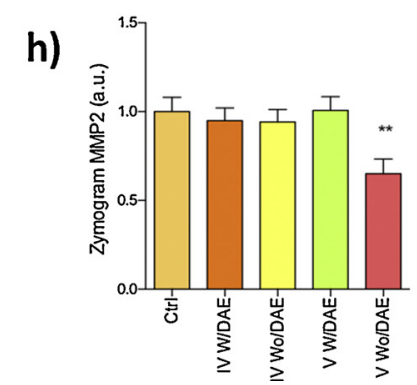

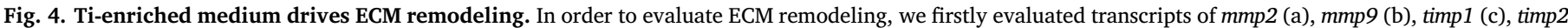

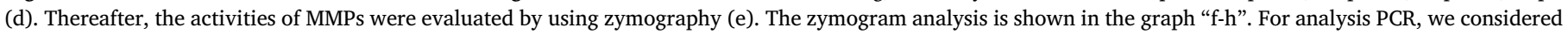

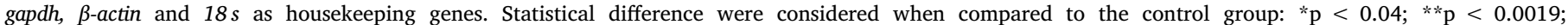

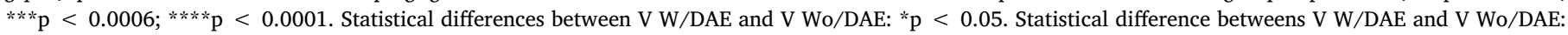
${ }^{*} \mathrm{p}<0.04 ; * * * * \mathrm{p}<0.0001$.

performance by evaluating pre-osteoblast viability, proliferation and ECM remodeling. To note, DAE-based surface modification is overspread used in dental implants, resulting a well-known micro-scaled roughness [22], able to increase of the contact surface with the environment. In sum, our data showed important differences on osteoblast performance, responding differentially to variations of titanium alloy compositions.

Titanium-enriched medium promoted up-expression of cyclin-dependent kinases (CDKs), preparing the cells to a proliferative phenotype. CDKs are important modulators in controlling cell division and modulating transcription in response to several extra- and intracellular signals [23]. Despite p21 up-expression, p15 gene was down-modulated, it being even more significant in response to DAE presented in both titanium grades considered in this study, once INK4 proteins contains p16INK4a, p15INK4b, p18INK4c and p19INK4d interact with the monomeric CDKs, distorting the cyclin interface and the ATPbinding pocket [24]. In addition, members of the Cip/Kip family of inhibitors (p21Cip1, p27Kip1 and p57Kip2) inhibit CDK-cyclin heterodimers [25]. At this point, the proliferative phenotype resulting in response to titanium-enriched medium guarantees a higher number of osteogenic cells, positively modulating further the bone de novo deposition at the end steps of the osseointegration-related biological sequence.

Firstly, cytoskeleton was dynamically rearranged by down- modulating the Rac/Cofilin pathway. These findings might be an important link between cell adhesion and the beginning of proliferation stage. We have proposed cytoskeleton rearrangement as a good parameter to be considered, once we showed a multitude of intracellular signaling able to govern cytoskeleton rearrangement during the first steps of the osteoblast adhesion [26-28]. Additionally, it seems to be a decisive mechanism driving osteoblast performance, once bone de novo deposition requires a dynamic cell adhesion and this performance compromises osseointegration mechanism.

On this sense, the cell anchoring to the substrate is both decisive and important aspect to be considered regarding the biomaterial-related cellular behavior. Thus, the mechanism related with the extracellular matrix (ECM) remodeling in response to biomaterials needs to be addressed. Briefly, ECM components are synthetized and secreted by active osteoblast in order to modify their microenvironment [29,30], providing a better cell anchoring. This mechanism is improved by the presence of the RGD peptides in the ECM-related proteins, which must be recognized by the integrins [31]. Here, we showed titanium-enriched medium down-modulates MMP2 activities, while their tissue inhibitors, timp1 and timp2 genes were up-expressed, suggesting a considerable diminution of the ECM remodeling in response to Ti-enriched medium. These results corroborates with previously published data, where we showed TIMP-2 is involved in the control of ECM remodeling in distinct phases of osteoblast differentiation [32], as well as 


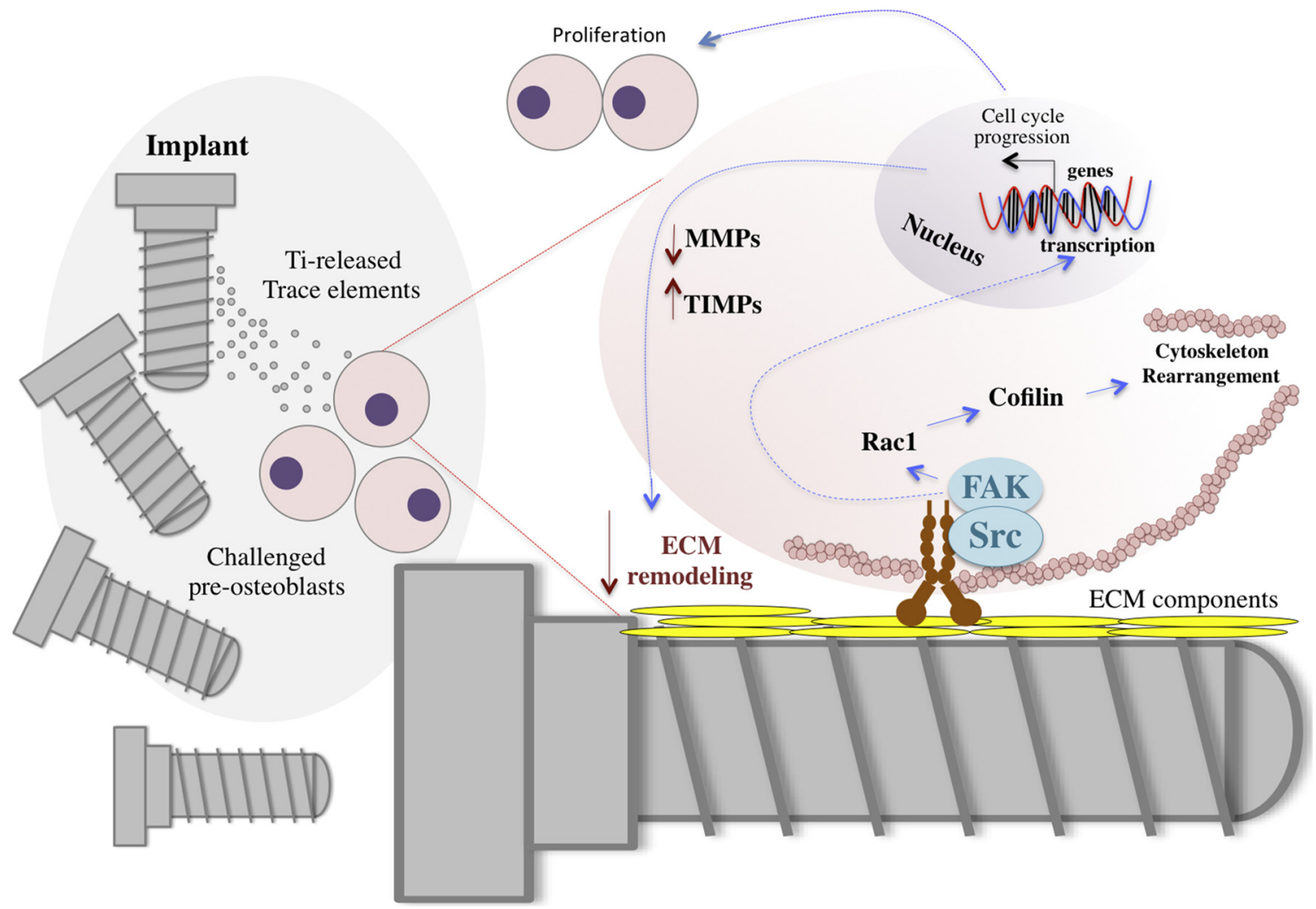

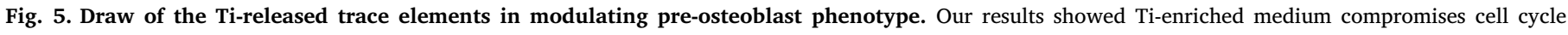

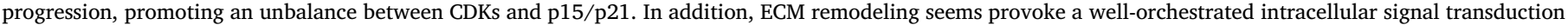
driving cytoskeleton rearrangement.

driving alveolar bone regeneration [33]. To note, MMPs are proteases able to breakdown the components of ECM in full, profoundly contributing with the tissue remodeling in health and physiopathological conditions [29]. Indeed, we suggested this diminution of the ECM remodeling as an event able to guarantee the adequate stability of the ECM and effectively contributing with cell adhesion and viability [34]. This hypothesis seems to be validated when we identified a significant up-expression of $\beta 1$-integrin in response to Ti grade $\mathrm{V}$, concomitant with their related downstream signaling proteins $s r c$ and fak, while MMP activity was decreased. To note, deposited matrix components promote immediate intracellular pathways upon integrin activation recruiting both Src and FAK into focal adhesion platforms, which guides cell adhesion, migration and proliferation, by triggering signals to drive cytoskeleton rearrangement $[3,5,27]$. Thus, a well-orchestrated ECM-remodeling seems to be a fundamental parameter to drive cellular performance peri-implants.

By associating the main findings obtained here in response to trace elements released from titanium devices, it is envisionable that part of the clinical effects on this matter have bearing on immune-modulatory properties by differentially required Rac activity, once Rac has been reported with several inflammatory-related pathways such as JAKSTAT signaling [35]. In addition, it might be relayed by the immunosuppressive properties of Arginine and Tryptophan metabolism, as suggested elegantly by Mondanelli et al. (2017), using dendritic cells [36]. However, we have used only in osteoblast to evaluate the effect of Ti-enriched medium and this is a limitation of this study to consider inflammatory landscape.

Taking our results into account, we showed for the first time that trace elements from titanium-based biomedical devices modulate the behavior of osteoblasts, resulting in a favorable microenvironment to drive cell anchoring, viability and the beginning of proliferative phenotype.

\section{Conflict of interest}

All the authors declare to have no conflict of interest with the materials used in the present study

\section{Acknowledgement}

The authors are grateful to FAPESP (\#2014/22689-3) and CNPq (\# 477452/2012-4) for the financial support. W.F.Z. is PQ-2 fellow from CNPq (\#301966/2015-0).

\section{References}

[1] P.I. Branemark, R. Adell, U. Breine, B.O. Hansson, J. Lindstrom, A. Ohlsson, Intraosseous anchorage of dental prostheses. I. Experimental studies, Scand. J. Plast. Reconstr. Surg. 3 (1969) 81-100.

[2] P.I. Branemark, R. Adell, T. Albrektsson, U. Lekholm, S. Lundkvist, B. Rockler, Osseointegrated titanium fixtures in the treatment of edentulousness, Biomaterials 4 (1983) 25-28.

[3] S. Gemini-Piperni, E.R. Takamori, S.C. Sartoretto, K.B.S. Paiva, J.M. Granjeiro, R.C. de Oliveira, W.F. Zambuzzi, Cellular behavior as a dynamic field for exploring bone bioengineering: a closer look at cell-biomaterial interface, Arch. Biochem. Biophys. 561 (2014) 88-98, https://doi.org/10.1016/j.abb.2014.06.019.

[4] C. von Wilmowsky, T. Moest, E. Nkenke, F. Stelzle, K.A. Schlegel, Implants in bone: part I. A current overview about tissue response, surface modifications and future perspectives, Oral Maxillofac. Surg. 18 (2014) 243-257, https://doi.org/10.1007/ s10006-013-0398-1.

[5] W.F. Zambuzzi, P.G. Coelho, G.G. Alves, A. Marque, D. De Caxias, R. De Janeiro, R. De Janeiro, F. Federal, Intracellular signal transduction as a factor in the development of " "smart" ' biomaterials for bone tissue engineering, Biotchnol. Bioeng. 108 (2011) 1246-1250, https://doi.org/10.1002/bit.23117.

[6] W.F. Zambuzzi, E.A. Bonfante, R. Jimbo, M. Hayashi, M. Andersson, G. Alves, E.R. Takamori, P.J. Beltrao, P.G. Coelho, J.M. Granjeiro, Nanometer scale titanium surface texturing are detected by signaling pathways involving transient FAK and Src activations, PLoS One 9 (2014) e95662, , https://doi.org/10.1371/journal. pone.0095662.

[7] R. Junker, A. Dimakis, M. Thoneick, J.A. Jansen, Effects of implant surface coatings and composition on bone integration: a systematic review, Clin. Oral Implants Res. 
20 (Suppl. (4)) (2009) 185-206, https://doi.org/10.1111/j.1600-0501.2009. 01777.x.

[8] L. Le Guehennec, A. Soueidan, P. Layrolle, Y. Amouriq, Surface treatments of titanium dental implants for rapid osseointegration, Dent. Mater. 23 (2007) 844-854, https://doi.org/10.1016/j.dental.2006.06.025.

[9] H. Terheyden, N.P. Lang, S. Bierbaum, B. Stadlinger, Osseointegration-communication of cells, Clin. Oral Implants Res. 23 (2012) 1127-1135, https://doi.org/10. 1111/j.1600-0501.2011.02327.x.

[10] K. Fischer, T. Stenberg, Prospective 10-year cohort study based on a randomized controlled trial (RCT) on implant-supported full-arch maxillary prostheses. Part 1: sandblasted and acid-etched implants and mucosal tissue, Clin. Implant Dent. Relat. Res. 14 (2012) 808-815, https://doi.org/10.1111/j.1708-8208.2011.00389.x.

[11] C.M. Abraham, A brief historical perspective on dental implants, their surface coatings and treatments, Open Dent. J. 8 (2014) 50-55, https://doi.org/10.2174/ 1874210601408010050.

[12] M.C. Rossi, F.J.B. Bezerra, R.A. Silva, B.P. Crulhas, C.J.C. Fernandes, A.S. Nascimento, V.A. Pedrosa, P. Padilha, W.F. Zambuzzi, Titanium-released from dental implant enhances pre-osteoblast adhesion by ROS modulating crucial intracellular pathways, J. Biomed. Mater. Res. A. 105 (Nov. (11)) (2017) 2968-2976, https://doi.org/10.1002/jbm.a.36150.

[13] E.F. Hartree, Determination of protein: a modification of the Lowry method that gives a linear photometric response, Anal. Biochem. 48 (1972) 422-427.

[14] S. Gemini-Piperni, R. Milani, S. Bertazzo, M. Peppelenbosch, E.R. Takamori, J.M. Granjeiro, C.V. Ferreira, A. Teti, W. Zambuzzi, Kinome profiling of osteoblasts on hydroxyapatite opens new avenues on biomaterial cell signaling, Biotechnol. Bioeng. 111 (2014) 1900-1905, https://doi.org/10.1002/bit.25246.

[15] W.F. Zambuzzi, C.V. Ferreira, J.M. Granjeiro, H. Aoyama, Biological behavior of pre-osteoblasts on natural hydroxyapatite: a study of signaling molecules from attachment to differentiation, J. Biomed. Mater. Res. A. 97 (2011) 193-200, https:// doi.org/10.1002/jbm.a.32933.

[16] S. Bertazzo, W.F. Zambuzzi, D.D.P. Campos, C.V. Ferreira, C.A. Bertran, A simple method for enhancing cell adhesion to hydroxyapatite surface, Clin. Oral Implants Res. 21 (2010) 1411-1413, https://doi.org/10.1111/j.1600-0501.2010.01968.x.

[17] S. Bertazzo, W.F. Zambuzzi, D.D.P. Campos, T.L. Ogeda, C.V. Ferreira, C.A. Bertran, Hydroxyapatite surface solubility and effect on cell adhesion, Colloids Surf. B Biointerfaces 78 (2010) 177-184, https://doi.org/10.1016/j.colsurfb.2010.02.027.

[18] W.F. Zambuzzi, K.B.S. Paiva, R. Menezes, R.C. Oliveira, R. Taga, J.M. Granjeiro, MMP-9 and CD68( + ) cells are required for tissue remodeling in response to natural hydroxyapatite, J. Mol. Histol. 40 (2009) 301-309, https://doi.org/10.1007/ s10735-009-9241-2.

[19] C.J.C. Fernandes, F. Bezerra, Mdas D. do Carmo, G.S. Feltran, M.C. Rossi, R.A. da Silva, P.M. de Padilha, W.F. Zambuzzi, CoCr-enriched medium modulates integrinbased downstream signaling and requires a set of inflammatory genes reprograming in vitro, J. Biomed. Mater. Res. A. 106 (2018) 839-849, https://doi.org/10.1002/ jbm.a.36244.

[20] F. Bezerra, M.R. Ferreira, G.N. Fontes, C.J. da Costa Fernandes, D.C. Andia, N.C. Cruz, R.A. da Silva, W.F. Zambuzzi, Nano hydroxyapatite-blasted titanium surface affects pre-osteoblast morphology by modulating critical intracellular pathways, Biotechnol. Bioeng. (2017), https://doi.org/10.1002/bit.26310.

[21] C.J.C. Fernandes, F. Bezerra, M.R. Ferreira, A.F.C. Andrade, T.S. Pinto, W.F. Zambuzzi, Nano hydroxyapatite-blasted titanium surface creates a biointerface able to govern Src-dependent osteoblast metabolism as prerequisite to ECM remodeling, Colloids Surf. B Biointerfaces 163 (2017) 321-328, https://doi.org/10. 1016/j.colsurfb.2017.12.049.

[22] D.M. Dohan Ehrenfest, L. Vazquez, Y.-J. Park, G. Sammartino, J.-P. Bernard, Identification card and codification of the chemical and morphological characteristics of 14 dental implant surfaces, J. Oral Implantol. 37 (2011) 525-542, https:// doi.org/10.1563/AAID-JOI-D-11-00080.

[23] M. Malumbres, M. Barbacid, Mammalian cyclin-dependent kinases, Trends Biochem. Sci. 30 (2005) 630-641, https://doi.org/10.1016/j.tibs.2005.09.005.

[24] P.D. Jeffrey, L. Tong, N.P. Pavletich, Structural basis of inhibition of CDK-cyclin complexes by INK4 inhibitors, Genes Dev. 14 (2000) 3115-3125.

[25] N.P. Pavletich, Mechanisms of cyclin-dependent kinase regulation: structures of Cdks, their cyclin activators, and Cip and INK4 inhibitors, J. Mol. Biol. 287 (1999) 821-828, https://doi.org/10.1006/jmbi.1999.2640.

[26] R. Milani, C.V. Ferreira, J.M. Granjeiro, E.J. Paredes-Gamero, R.A. Silva, G.Z. Justo, H.B. Nader, E. Galembeck, M.P. Peppelenbosch, H. Aoyama, W.F. Zambuzzi, Phosphoproteome reveals an atlas of protein signaling networks during osteoblast adhesion, J. Cell. Biochem. 109 (2010) 957-966, https://doi.org/10.1002/jcb. 22479.

[27] W.F. Zambuzzi, R. Milani, A. Teti, Expanding the role of Src and protein-tyrosine phosphatases balance in modulating osteoblast metabolism: lessons from mice, Biochimie 92 (2010) 327-332, https://doi.org/10.1016/j.biochi.2010.01.002.

[28] W.F. Zambuzzi, A. Bruni-Cardoso, J.M. Granjeiro, M.P. Peppelenbosch, H.F. de Carvalho, H. Aoyama, C.V. Ferreira, On the road to understanding of the osteoblast adhesion: cytoskeleton organization is rearranged by distinct signaling pathways, J. Cell. Biochem. 108 (2009) 134-144, https://doi.org/10.1002/jcb.22236.

[29] K.B.S. Paiva, J.M. Granjeiro, Matrix metalloproteinases in bone resorption, remodeling, and repair, Prog. Mol. Biol. Transl. Sci. 148 (2017) 203-303, https://doi. org/10.1016/bs.pmbts.2017.05.001.

[30] K.B.S. Paiva, J.M. Granjeiro, Bone tissue remodeling and development: focus on matrix metalloproteinase functions, Arch. Biochem. Biophys. 561 (2014) 74-87, https://doi.org/10.1016/j.abb.2014.07.034.

[31] M.A. Arnaout, B. Mahalingam, J.-P. Xiong, Integrin structure, allostery, and bidirectional signaling, Annu. Rev. Cell Dev. Biol. 21 (2005) 381-410, https://doi.org/ 10.1146/annurev.cellbio.21.090704.151217.

[32] W.F. Zambuzzi, C.L. Yano, A.D.M. Cavagis, M.P. Peppelenbosch, J.M. Granjeiro, C.V. Ferreira, Ascorbate-induced osteoblast differentiation recruits distinct MMPinhibitors: RECK and TIMP-2, Mol. Cell. Biochem. 322 (2009) 143-150, https://doi. org/10.1007/s11010-008-9951-x.

[33] T. Accorsi-Mendonca, K.B. da S. Paiva, W.F. Zambuzzi, T.M. Cestari, V.S. Lara, M.C. Sogayar, R. Taga, J.M. Granjeiro, Expression of matrix metalloproteinases-2 and -9 and RECK during alveolar bone regeneration in rat, J. Mol. Histol. 39 (2008) 201-208, https://doi.org/10.1007/s10735-007-9152-z.

[34] R.G. Wells, The role of matrix stiffness in regulating cell behavior, Hepatology 47 (2008) 1394-1400, https://doi.org/10.1002/hep.22193.

[35] W.J. Leonard, Role of Jak kinases and STATs in cytokine signal transduction, Int. J. Hematol. 73 (2001) 271-277.

[36] S. Pelletier, F. Duhamel, P. Coulombe, M.R. Popoff, S. Meloche, Rho family GTPases are required for activation of Jak/STAT signaling by G protein-coupled receptors, Mol. Cell. Biol. 23 (2003) 1316-1333. 